\title{
EXHUMAR LA DERROTA: FOSAS COMUNES DE \\ LA GUERRA CIVIL EN LA ESPAÑA DEL SIGLO \\ XXI
}

\section{EXHUMING THE DEFEAT: MASS GRAVES OF THE CIVIL WAR IN 21 ${ }^{\text {st }}$ _CENTURY SPAIN}

\author{
Francisco FerRándiz MARTíN" \\ ILLA-CSIC
}

Resumen: A partir del estudio de caso de dos fosas comunes exhumadas en un pequeño pueblo con ocho años de diferencia, abordo la transformación de las exhumaciones de la Guerra Civil (1936-1939) en España en la primera década del siglo XXI. La súbita aparición en la esfera pública de los esqueletos de civiles ejecutados por paramilitares franquistas ha suscitado acalorados debates sobre la forma de gestionar dichos restos en un estado democrático consolidado, y sobre la interpretación que debe darse a las iniciativas judiciales e institucionales que se han derivado de este proceso, a veces muy controvertidas. La peculiaridad del «modelo de subcontratación de los derechos humanos» que se sigue en España en relación con los crímenes de la Guerra Civil se sitúa en una perspectiva comparativa en el marco de los discursos y las prácticas transnacionales en materia de derechos humanos.

Palabras Clave: derechos humanos, justicia de transición, postconflicto, memoria, exhumaciones, fosas comunes, Guerra Civil española.

Aвstract: Based on a local case study of the exhumation of two mass graves in a small village, conducted eight years apart, I address the transformation of Civil War (1936-1939) disinterments in Spain over the last decade. The sudden visibility of skeletons of civilians executed by Franco's paramilitary in the public sphere has triggered heated debates both about how to handle them in a consolidated democratic state and

\footnotetext{
*Instituto de Lengua, Literatura y Antropología (CSIC). francisco.ferrandiz@cchs.csic.es El presente artículo es uno de los resultados del proyecto SUBTIERRO: Exhumaciones de fosas comunes y derechos humanos en perspectiva histórica, transnacional y comparada (Proyecto $\mathrm{I}+\mathrm{D}+\mathrm{i}$ CSO2015-66104-R).
} 
what to make of controversial judicial and institutional initiatives. The particularity of Spain's «human rights outsourcing model» regarding Civil War crimes is placed in comparative perspective within the framework of transnational human rights discourses and practices.

KEYwORDs: human rights, transitional justice, postconflict, memory, exhumations, mass graves, Spanish Civil War.

\section{Vidas más allá de la muerte}

El 30 de julio 2011 una tormenta mediática interrumpió la habitual calma de la temporada de vacaciones estivales en España. Una sepultura que albergaba los restos de diez personas en el cementerio municipal de Poyales del Hoyo, pequeño pueblo abulense de 600 habitantes a escasos 200 kilómetros al oeste de Madrid, había sido vaciada y trasladada por instrucciones del nuevo alcalde conservador. El alcalde había tomado esta decisión en respuesta a la petición de un familiar que deseaba trasladar el cadáver de su abuela al panteón familiar. Los restantes nueve cuerpos fueron reubicados en una sepultura cercana marcada con una sobria inscripción: fosa común. Una semana después, se celebró una tensa manifestación contra la decisión del alcalde y para pedir la restitución de los restos a la tumba original. La situación degeneró en un enfrentamiento público en la plaza del pueblo justo después de la misa dominical, y la Guardia Civil tuvo que intervenir para evitar una escalada de los altercados. Los manifestantes, en su mayoría representantes de «asociaciones para la recuperación de la memoria histórica» de fuera del pueblo, portaban una pancarta que decía: «¡Somos los nietos de los obreros que nunca pudisteis matar!».

Este incidente local, que en un principio no parecía revestir gran importancia, se difundió rápidamente a través de la prensa, emisoras de radio y programas de televisión y avivó las tensiones necropolíticas que se han desencadenado en el siglo XXI ${ }^{1}$ en relación con el destino de los cadáveres de la Guerra Civil (1936-1939). Porque estos huesos reubicados en Poyales no eran los esqueletos desechados y olvidados que los empleados de los cementerios suelen desenterrar para dejar espacio para otros nuevos, sino representantes paradigmáticos de algunos de los cadáveres contemporáneos más vulnerables y políticamente

\footnotetext{
1 Achille Mbembe (2003); João Biehl (2001).
} 
controvertidos de España: los de aquellos civiles ejecutados en la retaguardia del ejército de Franco en su avance durante la guerra y en los primeros ańos de la dictadura que le siguió. Los cadáveres de estas víctimas habían permanecido en gran parte abandonados en fosas comunes por todo el país durante décadas, sometidos a sucesivos regímenes de silencio, indiferencia y olvido ${ }^{2}$.

Esa situación cambió drásticamente hace una década. A partir de 2000, uno de los secretos más conspicuos de la democracia española quedó por fin expuesto a la vista del público: empezaron a aparecer y proliferar en los principales medios de comunicación, y después en Internet y las redes sociales, impactantes imágenes de esqueletos marcados por torturas perimortem y ejecuciones sumarias, exhumados en excavaciones arqueológicas por todo el país. Detrás de esta exposición descarnada del pasado traumático se encontraba la generación de los nietos de los vencidos en la Guerra Civil. Esta generación fue clave en el impulso de un movimiento asociativo heterogéneo y a veces fragmentado que ha colocado en el centro de su activismo político y moral la recuperación y la dignificación de la memoria de los vencidos en la Guerra Civil, lo que incluye, para algunas de ellas en un lugar muy destacado, la exhumación de las fosas comunes en todo el país.

El hecho de que a partir del año 2000 un creciente archipiélago de colectivos memoriales en Espańa empezara a volver la vista atrás con inquietud y asombro hacia la suerte que corrieron las diversas categorías de víctimas y verdugos de la Guerra Civil más de sesenta años después de los hechos, plantea dudas sustanciales sobre la gestión social del conflicto a largo plazo y los silencios y eufemismos en la memoria colectiva del país. Al mismo tiempo, socava la idea generalizada de que la prestigiosa transición a la democracia de finales de los años setenta y principios de los ochenta en España fue un éxito político, institucional y judicial que se puede imitar y repetir en otros contextos de tránsito de regímenes dictatoriales a democracias ${ }^{3}$. Muy al contrario, creo que el caso espańol muestra que las sociedades necesitan confrontar los aspectos más inquietantes de su pasado y que las estrategias políticas que privilegian barrer episodios oscuros de la historia «bajo la alfombra», pese a que pueden resultar efectivas durante determinados periodos de tiempo, resultan más desestabilizadoras a la larga. Es algo que puede ser inevitable cuando, con el paso de las generaciones, las culturas políticas emergentes experimentan lo que Hinton denomina "fricciones transicionales»

Francisco Ferrándiz (2011a); Francisco Ferrándiz (2014).

Laura D. EdLES (1998). 
en referencia a las tensiones y las discrepancias que necesariamente se generan al hacer frente a graves dificultades sociales y políticas en el contexto postconflicto ${ }^{4}$.

El caso español coincide, a su vez, con otras iniciativas institucionales y movimientos sociales de todo el mundo -tanto de carácter local como transnacional- que se están conformando en torno a las exhumaciones de fosas comunes ligadas a la maquinaria del terror de regímenes dictatoriales o totalitarios (u otros tipos de violaciones de los derechos humanos) y cuyo objetivo es crear una herramienta de verdad, justicia y reparación cada vez más prestigiosa. La apertura de fosas comunes relacionadas con violencias del pasado y del presente pone en marcha alambicados procesos políticos, judiciales, científicos, simbólicos y conmemorativos que están siendo cada vez más investigados por antropólogos de todo el mundo $y$, más en concreto, en España ${ }^{6}$. Por una parte, el análisis de las fosas comunes y las actividades que puedan generarse en torno a ellas permite la convergencia creativa de antropologías de la violencia, la muerte, el duelo, la victimización, los derechos humanos, el sufrimiento social, la memoria, el ritual, los medios de comunicación, la ciencia y la tecnología y el arte, entre otras. A su vez, las exhumaciones y otras acciones relacionadas con los restos y sus representaciones se perfilan como localizaciones etnográficas de enorme riqueza, y también complejidad, en las que se puede observar la circulación del trauma social y su influjo en el tejido social, condensando muchos procesos entrelazados que van desde emociones profundas o incidentes locales hasta la alta política o los convenios transnacionales.

Sin embargo, una antropología de las exhumaciones no puede detenerse en el estudio de las propias excavaciones o en debates metodológicos sobre la manera de investigarlas de manera significativa desde el punto de vista etnográfico. Resulta necesario trazar cuidadosamente los diferentes itinerarios que siguen los cuerpos una vez han sido extraídos de la fosa. En este sentido, tiene un gran valor la formulación de Katherine Verdery sobre la «vida política de

\footnotetext{
4 Alexander L. Hinton (2011); Paloma Aguilar (2000); Priscilla B. Hayner (2002); Richard WiLson (2003); Kimberly Theidon (2006).

5 Leigh Binford (1996); Paul Sant Cassia (2005); Zoe Crossland (2004); Heonik Kwon (2008); Sarah E. Wagner (2008); Antonius C.G.M. Robben (2002); Antonius C.G.M. RobBen (2005); Victoria SANFORd (2003).

6 Layla Renshaw (2011); Ignacio Fernández de Mata (2010); Ignacio Fernández de Mata (2016); Francisco Ferrándiz (2006); Francisco Ferrándiz (2008); Francisco Ferrándiz (2009); Francisco Ferrándiz (2010a); Francisco Ferrándiz (2010b); Francisco Ferrándiz (2011a); Francisco Ferrándiz (2013); Francisco Ferrándiz (2014).
} 
los cadáveres» ${ }^{7}$. Verdery, interesada en sacar a la luz las distintas modalidades de «necrofilia postsocialista» en Europa del Este y la antigua Unión Soviética (expresada por ejemplo, en el cambio de significado político y conmemorativo de muertos ilustres, momias, partes del cuerpo, estatuas, etc.), ha sugerido que el estudio de estos "cadáveres en movimiento» requiere que «[se preste] atención al simbolismo político; a los rituales y creencias sobre la muerte como, por ejemplo, las ideas sobre lo que constituye un "enterramiento apropiado"; a las conexiones entre los cadáveres particulares que se manipulan y los contextos nacionales e internacionales más amplios de la manipulación, y a la reevaluación, o reescritura, del pasado y la a creación o recuperación de la «memoria»" . En el caso español, los vidas y biografías políticas de esqueletos que están siendo exhumados, como cuerpo colectivo, han reclamado progresivamente más visibilidad y protagonismo dentro de la categoría más amplia de victimas de la Guerra Civil y de la represión franquista, en la que también se incluyen viudas y huérfanos, personas sometidas a abusos sexuales o torturas, presos, trabajadores forzados, refugiados, exiliados, purgados y nińos robados, entre otros?

A partir del estudio de un caso local, en este artículo me centraré en la transformación de las exhumaciones de la Guerra Civil en España en el siglo XXI, analizando la posible eficacia y también las carencias del modelo español de exhumación. Sin embargo, mi proyecto de investigación más amplio cubre una autopsia social ${ }^{10}$ que incluye las principales manifestaciones y recorridos de los restos exhumados en la España contemporánea, así como sus crecientes transacciones con discursos y prácticas transnacionales en materia de derechos humanos ${ }^{11}$, culturas cosmopolitas de la memoria ${ }^{12}$, y repertorios globalizados de la barbarie y la violencia en masa ${ }^{13}$.

\footnotetext{
7 Katherine VERDERY (1999).

Ibid., p. 3.

Santos Juliá (1999); Ricard Vinyes (2002); Javier Rodrigo (2008); Julián Casanova (2010); Paul Preston (2011).

10 Eric Klinenberg (2001).

11 Richard Wilson (2006); Jane K. Cowan (2006); Francisco Ferrándiz (2010a).

12 Daniel Levy y Natan Sznaider (2002).

13 Michael IgnatiefF (1998).
} 


\section{Exhumar la Guerra Civil española}

Uno de los aspectos más polémicos de los debates que se han producido en España con respecto a la Guerra Civil ha sido la magnitud y las características de la violencia contra civiles en la retaguardia de ambos bandos. Con los años, las controversias sobre la naturaleza y el alcance de la represión se han convertido en termómetro de la perversidad y la calidad amoral del enemigo. En cuanto al número de muertes violentas tras las líneas del frente, la historiografía contemporánea lo sitúa en 55.000 personas en la retaguardia republicana y hasta 150.000 en la retaguardia del ejército rebelde o «nacional»-incluidas unas 20.000 ejecuciones en la posguerra, aparte de quienes murieron en cárceles y campos de concentración durante y después del conflicto- o la violencia prácticamente no denunciada contra mujeres y niños ${ }^{14}$.

Como sostienen algunos historiadores, el hecho de que ambos bandos cometieran crímenes muy graves, dejando de lado las diferencias de escala mencionadas, no implica que fueran moralmente simétricos. En su libro Hasta la raíz, Rodrigo ofrece cinco razones por las que, desde un punto de vista historiográfico, hay diferencias fundamentales entre las acciones represivas llevadas a cabo detrás de las líneas del frente por el ejército rebelde y los grupos paramilitares asociados y los republicanos $(2008)^{15}$. En primer lugar, como se ha indicado, existe una diferencia estrictamente cuantitativa, relacionada con las cifras totales. Por otra parte, la violencia cometida por el bando franquista respondía a una inversión en terror bien diseñada y basada en una pedagogía de la sangre y era proporcionalmente mayor en comparación con el territorio controlado por el bando republicano ${ }^{16}$. La represión ejercida por las tropas rebeldes y los paramilitares contra los civiles también fue más intensa en las áreas que cambiaron de bando durante los primeros meses de la guerra. Otra diferencia estriba en el momento en el que la etapa inicial de terror en caliente indiscriminado sin garantías legales dio paso a una etapa de terror legal, no menos sangrienta, cuando en el bando rebelde se llevaron a cabo numerosas ejecuciones tras la celebración de juicios militares de dudosa ecuanimidad ${ }^{17}$. Finalmente, conforme avanzaba la guerra, fue aumentando notablemente la retaguardia nacional mientras se reducía la republicana, lo que incrementaba las

14 Santos Juliá (1999); Paul Preston (2011).

15 Javier Rodrigo (2008).

16 Véase también Paul Preston (2011).

17 Véase también Julián Casanova (1999). 
oportunidades de cometer crímenes y abusos en la primera mientras se reducía en la segunda.

En este contexto de elevado número de ejecuciones de civiles, para entender lo que está pasando en España desde el año 2000 es crucial resaltar que las exhumaciones contemporáneas no son excepcionales, sino que tan solo representan el último episodio en los sucesivos regímenes de exhumación y reinhumación de restos de la Guerra Civil que corresponden a distintas etapas necropolíticas ${ }^{18}$. Las exhumaciones de la posguerra comenzaron enseguida, en el marco del proceso de reconstrucción del país y de organización del nuevo estado dictatorial bajo el gobierno de Franco, con una narrativa oficial dominante nacionalcatólica de victoria militar anclada en cruzadas religiosas, heroísmo y martirio ${ }^{19}$. Posteriormente, a partir de finales de la década de 1950, más de 30.000 cadáveres de la Guerra Civil fueron exhumados y trasladados al Valle de los Caídos, que sigue siendo hoy día el principal bastión monumental del franquismo. Por su parte, de las fosas comunes con cadáveres de militantes o simpatizantes republicanos fueron abiertas de forma clandestina por familiares durante la dictadura y, muy especialmente, después de la muerte de Franco se llevaron a cabo un número todavía indeterminado pero muy relevante de exhumaciones sin apenas apoyo institucional o técnico ${ }^{20}$.

Sin embargo, hay un reconocimiento social de que un nuevo ciclo comenzó cuando el sociólogo y periodista Emilio Silva organizó la exhumación de una fosa común republicana en Priaranza del Bierzo, León, en la que se encontraban enterradas trece personas, entre ellas su abuelo. Esta exhumación fue la primera del ciclo más reciente que se llevó a cabo con la participación de expertos técnicos ${ }^{21}$. Desde entonces, esta exposición pública de los cuerpos ejecutados en excavaciones de fosas por todo el país ha demostrado tener implicaciones sociales, simbólicas, judiciales y políticas más amplias y de mayor alcance de lo que se podría haber imaginado en un primer momento ${ }^{22}$.

18 Francisco Ferrándiz (2014: 145-175).

19 Paloma Aguilar (2000); Zira Box (2010).

20 Francisco Ferrándiz (2009: 61-94) y Francisco Ferrándiz (2011b: 481-500).

21 Emilio Silva y Santiago Macías (2003).

22 Sobre el tema de las exhumaciones contemporáneas consideradas desde un punto de vista interdisciplinar y comparativo, véase C. Jerez-Farran y S. Amago, eds. (2010) y el número especial sobre "The Politics of Memory in Contemporary Spain» del Journal of Spanish Cultural Studies (2008), editado por Jo Labanyi. 
En términos de justicia transicional, el modelo español de exhumaciones del siglo XXI destaca como un caso especial, que se diferencia de procesos comparables en otras partes del mundo en los que las políticas de reparación están más en sintonía con la lógica contemporánea predominante de los discursos y procedimientos transnacionales en materia de derechos humanos, que incluyen la gestión institucional (que en España está aumentando a medida que se desarrollan políticas de memoria autonómicas), comisiones de la verdad, recogida de pruebas judiciales e incluso juicios contra los autores de los crímenes ${ }^{23}$. Esto se explica en parte por el tiempo transcurrido desde los homicidios, -que supera los plazos de prescripción en la legislación pena-y el diseño de la «transición» de los primeros ańos de democracia como mecanismo de reconciliación por los principales partidos políticos, que incluyó una ley de amnistía en 1977 y una voluntad, según el prestigioso historiador Santos Juliá, de echar al olvido los trapos sucios del pasado en aras de la convivencia ${ }^{24}$. Lo que ocurrió en Poyales del Hoyo en el verano de 2011 es consecuencia de esta orfandad institucional y judicial. Es también el resultado predecible de lo que denomino la subcontratación de las prácticas de derechos humanos en relación con la memoria de los vencidos en la Guerra Civil en la España contemporánea.

\section{Tres mujeres en la cuneta}

Los diez cadáveres que fueron objeto de la disputa del cementerio Poyales relatada anteriormente son el resultado de dos exhumaciones distintas en la vecina localidad de Candeleda, llevadas a cabo con ocho años de diferencia: la primera en 2002 (tres mujeres ejecutadas el 30 de diciembre de 1936), y la segunda en 2010 (seis hombres y una mujer ejecutados el 5 de octubre de 1936). En ambos casos, los vecinos de Poyales exhumados habían sido asesinados en acciones represivas de terror en caliente contra civiles llevadas a cabo por grupos paramilitares vinculados al ejército rebelde en su avance hacia Madrid durante las primeras etapas de la Guerra Civil. Me centraré en el análisis de dos aspectos principales, ambos cruciales para comprender la evolución necropolítica de las exhumaciones contemporáneas en España. En primer lugar, se corresponden con dos etapas muy diferenciadas en el proceso de excavación de fosas comunes

23 Priscilla B. Hayner (2002); Antonius C.G.M. Robben (2005); Sarah E. Wagner (2008); Alexander L. Hinton (2011); Paloma Aguilar y Leigh A. Payne (2016).

24 Laura D. Edles (1998); Santos Juliá (2003); Francisco Ferrándiz (2008). 
en la primera década del siglo XXI, pues se realizaron en los periodos anterior y posterior al desarrollo de políticas públicas regionales, el establecimiento de protocolos científicos estables, la Ley de Memoria Histórica (2007) y la fallida intervención judicial del juez Baltasar Garzón (2008). En segundo lugar, ambas exhumaciones estuvieron rodeadas de controversia sobre la «adecuada» protocolización técnica y política tanto de las excavaciones como de los rituales conmemorativos y funerarios derivados de ellas.

La excavación de Candeleda de 2002 fue la décima en España desde la apertura de la fosa de Priaranza ${ }^{25}$. Por tanto, corresponde a la primera etapa del proceso de exhumación. Las tres mujeres, una de ellas supuestamente embarazada, fueron exhumadas por dos jóvenes arqueólogos pertenecientes a la Sociedad de Ciencias Aranzadi y a la Asociación para la Recuperación de la Memoria Histórica $(\mathrm{ARMH})$, pionera en el país, que fue fundada por Emilio Silva y Santiago Macías en $2000^{26}$. Desde el punto de vista técnico, aunque de manera desigual, se han ido imponiendo en todo el país el uso sistemático de protocolos científicos, la primacía de la lógica forense en las excavaciones y la recuperación de restos, y la disponibilidad, el prestigio y la demanda de identificaciones genéticas (especialmente a partir de 2006) cuando ha habido recursos económicos. La primera excavación de Candeleda se llevó a cabo sin aplicar de manera sistemática ningún protocolo de búsqueda de personas desaparecidas ${ }^{27}$.

Después de trabajar todo el día, en torno a las 10 de la noche del 19 de octubre de 2002, los restos cadavéricos de las tres mujeres -Pilar Espinosa, Virtudes de la Puente y Valeriana Granada- fueron devueltos a sus familiares in situ basándose en las pruebas circunstanciales disponibles, así como en los recuerdos y la intuición de los parientes presentes, que estuvieron de acuerdo en qué restos correspondían a qué familias. En un ambiente de intensa emoción, los arqueólogos entregaron los restos a los familiares en cajas de cartón

25 La Sociedad de Ciencias Aranzadi, institución científica vasca que ha llevado a cabo una buena parte de las excavaciones desde 2000, ofrece la lista más fiable de exhumaciones disponible en Espańa. Véase http://www.politicasdelamemoria.org/2015/09/154-listado-de-exhumaciones-llevadas-a-cabo-en-espana-desde-el-ano-2000/.

26 Para más información sobre la ejecución, de acuerdo con fuentes orales, y sobre el impacto local y la gestión de la exhumación, véanse Silva y Macias (2003: 219-224) y TremLETT (2006: 19-43). Un extracto del capítulo de Tremlett sobre la primera exhumación de Candeleda se publicó en The New York Times el 11 de abril de 2007.

27 U.N. Doc. E/ST/CSDHA/.12 (1991). Véase la versión revisada (2016) en: http://www. ohchr.org/Documents/Issues/Executions/MinnesotaProtocolInvestigationPotentiallyUnlawfulDeath2016.pdf. 
independientes sin más formalidad. No hubo presencia de jueces ni de funcionarios del Estado.

Desde el comienzo de las exhumaciones, una motivación fundamental ha sido la de proporcionar "digna sepultura» a los cuerpos que, de acuerdo con familiares y activistas, fueron «sepultados como perros» en las condiciones establecidas por sus asesinos ${ }^{28}$. De acuerdo con esta lógica, no solo los mataron, sino que los excluyeron de su comunidad de muerte significativa. Los destinos más comunes para los cuerpos exhumados son los cementerios municipales, aunque las asociaciones han discrepado profundamente sobre la forma tanto de exhumarlos como de reinhumarlos (por ejemplo, funeral religioso o secular, predominio de expresiones políticas o duelo personal, etc.). Las divergencias necropolíticas sobre el destino de los republicanos exhumados estallaron unos días después, cuando los familiares intentaron reinhumar a las tres mujeres en el cementerio de Poyales. Nadie había previsto que esto sucediera. El alcalde, miembro del Partido Popular (PP), formación política que se opone a este proceso por considerarlo innecesario, guerracivilista y divisivo, se negó en un principio a facilitar la inhumación en el cementerio de las tres mujeres ejecutadas, y uno de sus funcionarios alegó falta de espacio. Este razonamiento resume de manera fehaciente más de seis décadas de abandono de las fosas comunes de los vencidos. Finalmente, en medio de la controversia, la corporación municipal cedió ante la presión local y mediática -la historia de Pilar Espinosa y su hija Obdulia Camacho llegó incluso a The New York Times-, lamentó el «malentendido» y cedió una sepultura municipal ${ }^{29}$.

Los civiles ejecutados por las fuerzas franquistas en la retaguardia han permanecido en un limbo legal durante décadas. Las fosas comunes de los derrotados, que jamás se investigaron durante el franquismo, hoy en día no se pueden considerar formalmente escenas del crimen, pues se trata de delitos que prescribieron de acuerdo con el derecho penal nacional y la Ley de Amnistía aprobada por el Parlamento en 1977 tras la muerte de Franco. En cuanto al abandono institucional, poco reconocimiento se podía esperar durante la dictadura (1939-1975), debido en parte a que el régimen franquista se sirvió de las fosas comunes en su campańa de intimidación y terror, sobre todo en el ámbito rural. En las primeras dos décadas y media de democracia, ni el Estado ni las comunidades autónomas desarrollaron políticas públicas en relación con las fosas comunes de los

28 Sobre la animalización de seres humanos y sus cadáveres, véanse João BIEHL (2001); Francisco Ferrándiz (2009).

29 Giles Tremlett (2006). 
derrotados. Se necesitó tiempo para que las instituciones respondieran, paulatinamente y de forma irregular, a las nuevas demandas de justicia y reparación de las acciones de violencia que ponen al descubierto las exhumaciones impulsadas inicialmente desde la sociedad civil.

En las primeras exhumaciones como la de Candeleda, los familiares, las asociaciones, los propietarios de los terrenos o las autoridades municipales, según las circunstancias, decidían en cada caso la forma de gestionar todos y cada uno de los detalles concretos. Macías me explicó cómo fue cobrando impulso la exhumación.

Estábamos abrumados. Todo esto estaba empezando y nos faltaba experiencia. Después de la excavación de Piedrafita de Babia (León) en el verano de 2002, se publicó un artículo en el diario El País titulado "La tierra devuelve a sus muertos». Debido a la cobertura que recibió el asunto en los principales medios de comunicación, la ARMH comenzó a recibir centenares de peticiones de ayuda para encontrar personas desaparecidas en todo el pais. El caso de Poyales-Candeleda simplemente fue más rápido que los demás. Recibiamos llamadas de activistas locales, llegábamos al lugar y empezábamos a excavar (Entrevista del autor).

Emilio Silva, cofundador junto a Macías de la ARMH, considera que la espiral de atención mediática que suscitaron estas primeras excavaciones, incluida la presencia de la BBC en la exhumación de Candeleda, ayudó a dar a sus actividades un tono "políticamente correcto" en un entorno de gran ansiedad personal, hostilidad política e incredulidad social.

La ARMH asumió los aspectos técnicos del proyecto, mientras que la agrupación local de Izquierda Unida (IU), coalición vinculada al Partido Comunista, se hacía cargo de la infraestructura y diseñaba el trabajo simbólico y político. De hecho, la excavación de Candeleda ejemplifica una primera fase en una controversia muy acusada dentro del movimiento asociativo sobre la gestión jurídica, política y simbólica de los cuerpos exhumados. Los activistas locales, abiertamente favorables a la "dignificación» de los restos recuperados en el marco de rituales políticos vinculados con los repertorios de conmemoración del Partido Comunista y un renacido republicanismo, tuvieron desacuerdos con los representantes 
de la ARMH, más partidarios de dejar que los familiares de las víctimas hicieran las cosas a su manera y, por tanto, gestionaran de manera autónoma sus actos de duelo, incluidos los rituales religiosos si así lo deseaban. En términos de Bull y Hansen, aunque con matices, el Foro desplegaría desde sus orígenes un registro memorial antagonista, de carácter explícitamente antifascista y vinculado a la recuperación de una memoria política, mientras que la ARMH iría insertándose progresivamente en una trama memorial más cosmopolita, vinculada con los discursos y prácticas transnacionales de los derechos humanos y más centrada en los derechos de las víctimas ${ }^{30}$.

Durante la exhumación se organizó una marcha de Candeleda a la fosa común portando una bandera republicana - prohibida durante el franquismo y convertida ahora en un símbolo antimonárquico no oficial, cada vez más extendido- y una banda de música local interpretó himnos republicanos. Miembros de la ARMH trataron de convencer a los participantes en la marcha para que no llegaran hasta la fosa con la banda. El desacuerdo sobre la ritualización política adecuada de la excavación se mantuvo durante todo el día. Solo unas semanas después de la exhumación se fundó el Foro por la Memoria, que representará a partir de entonces la cultura política exhibida de manera embrionaria por los activistas locales de Candeleda. El Foro y la ARMH son las asociaciones más influyentes. Estas dos sensibilidades políticas, interrelacionadas pero muy diferenciadas, se han visto envueltas en numerosos desacuerdos, pero también han compartido, aunque menos frecuentes, momentos de unidad estratégica. Sin embargo, la tensión entre ambas ha sido un elemento crucial en la estructuración del campo asociativo de la «memoria histórica».

A medida que el interés por las exhumaciones y los restos exhumados aumentaba en los medios y se transformaba en consecuencia la cultura política en torno a su memoria y dignificación, la fosa exclusivamente de mujeres de Candeleda se convirtió, para el movimiento asociativo, en un ejemplo representativo de la barbarie y las atrocidades atribuidas a represión franquista. Los activistas asociaron esta ejecución con otro caso aún más paradigmático, el de las Trece Rosas, un grupo de mujeres jóvenes afiliadas a un partido izquierdista -las Juventudes Socialistas Unificadas- que fueron ejecutadas el 5 de agosto de 1939 en Madrid tras el final de la guerra. Santiago Macías seleccionó el caso de Candeleda para el conocido libro Las fosas de Franco que escribió con Emilio Silva (2003). El 14 de abril de 2006, la asociación local que trabajaba en Candeleda y Poyales erigió

30 Ana Cento Bull y Hans Lauge Hansen (2016). 
junto a la fosa un monolito que representaba un paredón de fusilamiento con numerosos impactos de bala, dedicado a la «mujer republicana, a su dignidad y sacrificio».

\section{Refriegas técnicas, políticas y legales}

Las exhumaciones empezaron a proliferar a partir de 2002 sin supervisión institucional centralizada ni implicación legal. En este contexto, el médico forense Francisco Etxeberria dio a conocer el texto clave de la captura cientifica progresiva de los restos exhumados, primero publicado online y después como capítulo de un libro colectivo ${ }^{31}$. En ausencia del poderoso paraguas institucional que brinda la escena judicial del crimen como entorno de investigación prevalente, la amplia difusión de este protocolo y el fuerte compromiso asumido por Etxeberria y su equipo basado en la Sociedad de Ciencias Aranzadi han sido cruciales en el reconocimiento de la importancia que reviste un régimen arqueológico y sobre todo forense de la verdad y la estética en la gestión de las exhumaciones y en la construcción general de la memoria histórica en España. Aunque carece de cobertura judicial, esta modalidad freelance de producción del conocimiento sobre las violaciones de los derechos humanos se basa también en un método riguroso, la lógica probatoria, las nuevas modalidades de imágenes técnicas y digitales, la custodia científica, la elaboración de archivos electrónicos y la creciente popularidad de la identificación del $\mathrm{ADN}$ y sus lógicas de parentesco genético y certidumbre estadística ${ }^{32}$.

A partir de entonces, las continuas exhumaciones y las crecientes demandas de los familiares de las víctimas dieron lugar a la elaboración de políticas de la memoria pública en distintas regiones del país, sobre todo en las gobernadas por el Partido Socialista (PSOE) y otros partidos de izquierda (IU). Algunas de ellas incluyeron la aprobación progresiva de protocolos técnicos para las exhumaciones. Sorprendentemente, el protocolo nacional, basado en guías metodológicas internacionales para la investigación de violaciones de los derechos humanos, tuvo que esperar hasta 26 de septiembre de 2011, cuando se publicó en el Boletín

31 Francisco EtXeberria (2004).

32 Thomas Laqueur (1989); Thomas Laqueur (2002); Zoe Crossland (2011); Sarah E. Wagner (2008); Michael Elkin (2006); Alfredo GonzÁlez-Ruibal (2007); Luis Ríos, José Ignacio Casado y Jorge Puente (2010); Layla Renshaw (2011); Thomas Keenan y Eyal WeIZMAN (2012). 
Oficial del Estado, después de haberse realizado más de 280 exhumaciones. La escala y los detalles de este intrincado proceso de políticas locales, regionales y nacionales de la memoria en España son muy complejos y quedan fuera del alcance de este texto. Mencionaré brevemente dos momentos cruciales que han afectado al gobierno y al sistema judicial del país.

En primer lugar, en su discurso inaugural en abril de 2004, el presidente del gobierno entrante, el socialista José Luis Rodríguez Zapatero, se refirió a su abuelo Juan Rodríguez Lozano -capitán del ejército que se mantuvo fiel a la República y fue juzgado y fusilado en 1936-, como la principal inspiración de su vocación política. Este guiño biográfico a los vencidos y ejecutados en la Guerra Civil fue entendida, inicialmente, como una oportunidad política prometedora por muchos de los miembros de la compleja comunidad memorialista. A medida que el trabajo asociativo y las exhumaciones cobraban impulso y visibilidad pública, en noviembre de 2004 Zapatero nombró a su vicepresidenta Teresa Fernández de la Vega para dirigir una "Comisión Interministerial para el estudio de la situación de las víctimas de la Guerra Civil y del franquismo" y a elaborar un anteproyecto de ley para ofrecer un «adecuado reconocimiento y satisfacción moral a las víctimas». En diciembre de 2005 el gobierno de Zapatero estableció una línea de financiación para las actividades relacionadas con las víctimas, que empezó a ser efectiva en 2006. Por último, a finales de 2007, el gobierno aprobó la «Ley 52/2007, de 26 de diciembre, por la que se reconocen y amplían derechos y se establecen medidas en favor de quienes padecieron persecución o violencia durante la guerra civil y la dictadura» en el parlamento, en medio de una controversia política y del absoluto rechazo de las principales asociaciones, que protestaron enérgicamente. La sección referida a las exhumaciones (arts. 11-14) establecía que las administraciones públicas estaban obligadas a «facilitar a los descendientes directos de las víctimas que así lo soliciten» aquellas actividades de «indagación, localización e identificación de las personas desaparecidas violentamente durante la Guerra Civil o la represión política posterior y cuyo paradero se ignore». Pese a que la ley establecía que «los hallazgos se pondrán inmediatamente en conocimiento de las autoridades administrativas y judiciales competentes», en la práctica legalizaba un modelo de subcontratación de los derechos humanos por el que el Estado facilitaba asistencia y financiación (limitadas) al tiempo que transfería la responsabilidad de la investigación, las identificaciones de la exhumaciones y la gestión global de los restos de los ejecutados a las asociaciones y grupos de familiares y, en última instancia, a los equipos técnicos que colaboran con ellos. 
En segundo lugar, durante los debates parlamentarios sobre la ley, muchas asociaciones tuvieron la sensación de que la ley no iba a estar a la altura de sus demandas de "verdad, justicia y reparación» y no revertía lo que algunas asociaciones como el Foro denominan «modelo español de impunidad». Estratégicamente, algunas asociaciones recurrieron a la Audiencia Nacional-que había recibido la atención internacional con el procesamiento de Pinochet en 1998 por uno de sus jueces más destacados, Baltasar Garzón- con el fin de conectar los crímenes cometidos de acuerdo con el derecho internacional de los derechos humanos. Garzón respondió a las demandas de familiares y asociaciones abriendo una causa contra el franquismo en octubre de 2008, que traducía aspectos de la legislación internacional en materia de derechos humanos y los aplicaba al caso español. Esta causa tuvo una importante repercusión mediática internacional y sirvió para aplicar de conceptos no prescriptivos del derecho internacional de los derechos humanos, como desapariciones forzadas o crimenes contra la humanidad, a los cuerpos de los ejecutados que habían sido enterrados en fosas comunes. El recurso de Garzón a la justicia internacional recibió una respuesta negativa instantánea por parte del poder judicial español, que expuso dos argumentos principales: primero, si las supuestas acciones fueron crímenes, ya habían prescrito según la legislación penal española; además, en 1977 las Cortes aprobaron por abrumadora mayoría una Ley de Amnistía que sellaba la reconciliación e impedía la posibilidad de exigir responsabilidades penales por crímenes del pasado. A la luz de estas objeciones, Garzón se vio obligado a reconocer su falta de jurisdicción y retiró la acusación cuatro semanas después, sugiriendo que la competencia legal sobre tales crímenes contra la humanidad recaía en los juzgados territoriales.

Finalmente, Garzón fue denunciado por dos asociaciones derechistas por incumplimiento de sus obligaciones legales y se enfrentó a una campaña en su contra que llegó al Tribunal Supremo. Mientras tanto, fue suspendido temporalmente de sus funciones cuando se abrió formalmente el juicio oral contra él en mayo de 2010. El 27 de febrero de 2012 resultó finalmente absuelto, pero ya había sido condenado y suspendido por otra. A pesar de este revés judicial, los argumentos legales transnacionales que estableció en su causa judicial, una vez asumidos por asociaciones, políticos, académicos y medios de comunicación, tuvieron una intensa vida social, transformando la percepción de las represalias contra civiles durante la guerra e, igualmente importante, enmarcando los restos exhumados bajo una nueva luz. Dado su destacado perfil internacional, Garzón fue un factor importante para dirigir la atención mundial a los acontecimientos en España, acercando los procesos legales globales a los huesos exhumados, además de contribuir a ubicar las exhumaciones contemporáneas en el ámbito 
transnacional de los derechos humanos. Sin embargo, después de este breve e intenso entrecruzamiento de la justicia nacional e internacional, los cuerpos ejecutados en fosas comunes españolas regresaron a una situación históricamente alegal.

\section{Segundo asalto en Candeleda y Poyales}

Durante algunos años, Candeleda y Poyales permanecieron en buena medida ajenos a estos acontecimientos tan polémicos y de largo alcance. Ambos municipios están en la comunidad de Castilla y León, gobernada desde 1987 por el Partido Popular (PP), que ha se ha mostrado muy reacio a tomar parte activa en el proceso de exhumación, cuando no abiertamente contrario ${ }^{33}$. A diferencia de otras regiones, aquí no se ha desarrollado ninguna política pública de la memoria, y las asociaciones y los familiares dependen de dinámicas locales y de negociaciones específicas de cada caso. La segunda exhumación de vecinos de Poyales en Candeleda comenzó a finales de marzo de 2010. Siguiendo la tónica dominante en todo el país, la tensión entre la ARMH y el Foro y volvió a aflorar en este caso. La tumba había sido investigada por la asociación local del Foro -Foro por la Memoria del Valle del Tiétar y La Vera-, junto con un grupo de arqueólogos. Julio Serapio, un pastor que tenía doce años en el momento de la masacre, les ayudó a localizar la fosa. Había sido testigo de cómo habían arrastrado los siete cadáveres por la pendiente a pocos metros de distancia de la carretera, antes de lanzarlos a la fosa, que se encontraba en una finca privada. Después de que los familiares presentaran una petición formal, se llegó a un acuerdo entre la asociación, el alcalde de Candeleda y el propietario del terreno para realizar la excavación. El dueño había comprado aquella parcela hacía unos veinte años, pero, me transmitió, nadie le dijo nunca que hubiese en ella una fosa común de la Guerra Civil. De algún modo, estaba deseando desembarazarse de ella, y por eso accedió a la exhumación. Sin embargo, se suscitaron desacuerdos sobre la forma de proceder, lo que dio al traste, inicialmente, con la operación. La ideología y las directrices de exhumación del Foro establecen la importancia crucial de dotar de un nítido perfil político a todas las actuaciones relacionadas

33 Un ejemplo de esto es la opinión de Jorge Fernández Díaz, que fue uno de los portavoces del PP en los debates parlamentarios sobre la Ley de Memoria Histórica, calificó de «vergonzosa»e «irresponsable» dicha ley. 
con la recuperación de la memoria histórica ${ }^{34}$. Cuando los arqueólogos estaban limpiando la fosa y encontraron los primeros huesos, algunos activistas extendieron banderas republicanas alrededor del área excavada. No hay consenso sobre lo que ocurrió justo después o cuál fue la chispa que prendió la llama. El Foro sostiene que el propietario ya había decidido prohibir cualquier simbología política en su terreno y comunicó al alcalde que retiraba el permiso para la excavación. El propietario me dijo después que se había enterado del revuelo en los medios de comunicación, a pesar de que había dejado claro que, aunque "por supuesto» apoyaba el derecho de los familiares a desenterrar a sus muertos, no quería ningún «mitin político» en su finca. Sea como fuere, la excavación se detuvo a consecuencia de este desacuerdo.

Dos meses después, la ARMH reanudó la exhumación. Desde 2007, la asociación había consolidado un equipo técnico con sede en Ponferrada (León), que dependía en gran medida de las subvenciones gubernamentales anuales otorgadas por el Ministerio de la Presidencia para su funcionamiento. La excavación fue coordinada nuevamente por Macías, como había ocurrido ocho años antes en la otra fosa de Candeleda. Desde su fundación, como vimos, la ARMH ha asumido un perfil político menos marcado que da prioridad a la voluntad y las preferencias de los familiares más que a un programa conmemorativo con una orientación política definida. Esta posición abierta ha sido considerada por el Foro y algunas otras asociaciones como una traición a la naturaleza política de los crímenes y a los ideales republicanos de los ejecutados, lo que ha costado a la ARMH la dura acusación de ser los «neoliberales de la memoria», es decir, de fomentar memorias privadas, diferenciadas de las políticas y, supuestamente, privilegiando el interés personal sobre los ideales políticos de los fusilados ${ }^{35}$.

El impulsor de la exhumación había sido Lázaro Martín, cuyo padre y abuelo fueron ejecutados juntos en ese lugar cuando él tenía ocho años. Lázaro, su hija Julia, su hermana y su sobrina acudían a menudo a la excavación, atentos a los restos humanos y objetos personales que iban apareciendo, reconstruyendo retazos de la historia familiar y del asesinato, y mostrando al equipo y a los presentes fotografías antiguas de algunos de los muertos y los familiares supervivientes. «Siempre oí que había siete enterrados aquí. Todo el mundo lo sabía en el pueblo», señaló Lázaro la primera vez que vino a la excavación. En una entrevista en

\footnotetext{
34 Estas directrices se pueden descargar en la página web del Foro: http://www.foroporlamemoria.info/.

35 Francisco Ferrándiz (2006).
} 
vídeo que grabamos a unos metros de la excavación, compartió con nosotros sus recuerdos sobre los asesinatos y sus secuelas.

"Los metían en un calabozo, una nave que tenían allí en Poyales, y de allí los sacaban por la noche... Y aquí vinieron, yo he estado conociendo hasta... se han muerto todos... hasta hace poco, los que vinieron a matarlos... unos chavalotes de dieciocho o veinte años tenían o así, que estaban en la guerra más o menos... vinieron por lo menos seis u ocho del pueblo... que han estado viviendo hasta hace poco... a uno le eché yo mano un día y le pegué un golpe... me cansó, me dijo que yo era un cacique y yo le dije 'tú eres un verdadero criminal'... Había muchos malos... Mi madre por aquí [el lugar de la fosa] nunca pasó para ir a Candeleda. Cogía un camino abajo por aquellos montes, nunca pasó por aquí... Trabajamos mucho mucho en el campo... tuve que ser un esclavo toda la vida, yo anduve descalzo durante años... pasábamos hambre, mucha necesidad, y siempre con remiendos, pasando más bien hambre y pasando penas, porque nos tuvimos que ir a casa de un abuelo mío, que nos recogió... del lado de mi madre claro... Yo empecé a trabajar a los diez años... Me quedé en el pueblo por no dejar a mi madre y a mis tres hermanas solas, una tenía seis años, la otra cuando murió mi padre tenía tres... Nos quitaron todo, luego tuvimos que ir a pagar al Tribunal de Responsabilidades Políticas en Madrid... a pagar 3.000 pesetas para devolvernos las fincas... como si fueran de ellos... era mucho dinero en aquellos tiempos ${ }^{36}$.

Macías acompañó a Lázaro al Archivo Municipal de Poyales para confirmar las identidades de las siete personas inhumadas, tres de las cuales eran desconocidas para el equipo de investigación al haberse perdido su memoria en el pueblo. Se averiguó entonces que los tres muertos anónimos eran miembros de una misma familia, una pareja de 82 y 62 años y su hijo de 24, sin descendientes. Según confirmaban los certificados de defunción, todos murieron como consecuencia de "la guerra", al mismo tiempo y en el mismo lugar. Cuando ya era evidente la presencia de restos humanos, siguiendo una práctica que han ido adoptando el Foro y la ARMH en un intento por conseguir que las autoridades investiguen sus hallazgos como crímenes, Macías instó a los jueces provinciales y a la Guardia

36 En torno a las narrativas sobre fosas comunes, véase Francisco FERRÁndiz (2008). Sobre el Tribunal Nacional de Responsabilidades Políticas véase Manuel Álvaro Dueñas (2006). 
Civil a investigar el lugar del enterramiento argumentando que los esqueletos mostraban señales de violencia. Macías también pidió «vigilancia preventiva del lugar de la actuación» a la Guardia Civil durante la exhumación. René Pacheco, el arqueólogo que dirigía la excavación, fue llamado después por la policía judicial para declarar en la comisaría sobre las motivaciones y los hallazgos de la ARMH. Pero, al igual que en la mayoría de las exhumaciones realizadas en todo el país, una vez que se establece la prescripción del delito en el código penal, el caso es archivado. En ausencia de un protocolo nacional para las exhumaciones hasta finales de 2011, la excavación procedió según el patrón técnico establecido por la ARMH, que trata las fosas comunes como «enterramientos primarios sincrónicos». Sobre el terreno, los restos se separaron de manera «individualizada», se numeraron correlativamente, se fotografiaron metódicamente empleando técnicas arqueológicas de reunión de pruebas, se «levantaron» sistemáticamente de la tumba y se colocaron en cajas individuales junto a sus pertenencias ${ }^{37}$.

Al finalizar la excavación, los cuerpos fueron trasladados al laboratorio de la sede de la ARMH en Ponferrada, donde continuaron su proceso de inscripción cientifica en las líneas descritas anteriormente: se limpiaron, procesaron y analizaron a fondo de acuerdo con su protocolo de laboratorio. En ausencia de respaldo legal para la excavación, como en la gran mayoría de los casos en el país, el informe de Candeleda tenía un valor meramente informativo y de archivo, y expresaba los esfuerzos técnicos para confirmar la hipótesis de muerte violenta y lograr identificaciones concretas. El informe analizaba a los «individuos» uno a uno. Cada uno de ellos se representó en un diagrama de diferente color con el software Micrografx Designer, indicando la posición en la que fueron encontrados en la tumba. El individuo número 7 era el que tenía señales más claras de ejecución: un orificio de bala de salida en el hueso parietal derecho del cráneo. También se encontraron un casquillo de cartucho de rifle caso Mauser y restos de una bala detonada. La disposición anatómica indicaba que al menos cuatro de ellos tenían las manos atadas a la espalda cuando fueron ejecutados. El hallazgo de un pendiente confirmó la presencia de una mujer. Todo esto coincidía con la premisa de la ejecución de siete personas en los términos ya establecidos por testimonios orales y por los certificados de defunción.

Una vez redactado el informe arqueológico y forense, el equipo de la ARMH, se puso en contacto con los familiares para preparar la devolución de los restos a Poyales. El 11 de marzo de 2011 llegaron al pueblo en la furgoneta de la

37 Zoe Crossland (2004); Layla Renshaw (2011). 
asociación los restos exhumados en siete contenedores de plástico rígido procedentes del laboratorio. En la última década, los rituales de devolución de los restos a familiares y comunidades han pasado a ser un canal fundamental para la celebración y el despliegue público de la memoria de los civiles ejecutados en la guerra. Aunque la estructura de estos rituales de devolución suelen similares en todo el país -acto público de rememoración (a menudo con presentaciones en PowerPoint del análisis científico), cortejo fúnebre por las calles del pueblo, reinhumación (en su mayoría en cementerios), comida popular-, la gestión concreta de los restos varía según las regiones o las afinidades políticas de las asociaciones o familiares. La modalidad predominante de entierro fue inicialmente la comunidad de muerte: dado que fueron asesinados juntos, se les vuelve a inhumar juntos. La disponibilidad de financiación estatal para llevar a cabo algunas pruebas de ADN en el periodo 2006-2012 ha fomentado la demanda de identificaciones y enterramientos individuales, aunque esto afecta a un número relativamente pequeño de situaciones. Sin embargo, dado que el Estado ha eludido la coordinación de las identificaciones y la creación de una base de datos centralizada, no se ha establecido institucionalmente una burocracia de identidad postmortem ${ }^{38} \mathrm{y}$ hay pocos equipos con capacidad para llevar a cabo procedimientos de identificación genética ${ }^{39}$.

Como en la mayoría de los casos en todo el país, la devolución de los restos al municipio tras la investigación de laboratorio se realizó sin grandes tensiones. Se celebró un breve acto público al que asistieron unas cincuenta personas en un centro comunitario y se expusieron públicamente los restos de las siete personas en contenedores de plástico durante unos minutos. A diferencia de otros casos ${ }^{40}$, no hubo representación institucional formal del ayuntamiento ni de ninguna otra autoridad local o regional. Macías celebró el cierre de un «episodio que lamentablemente se repite en miles y miles de lugares de este país... en este caso siete víctimas de este pueblo vuelven a su casa...»A A continuación, se quejó de que el compromiso institucional y legal con los desaparecidos en España distaba mucho del que se daba en otros casos internacionales muy conocidos, y que las asociaciones no deberían ser las únicas responsables de gestionar la aplicación de principios básicos de los derechos humanos en el país, como era el caso de las exhumaciones.

\footnotetext{
38 Sarah E. WaGner (2008).

39 Luis Ríos, José Ignacio Casado y Jorge Puente (2010).

40 Véase por ejemplo Julián López y Francisco Ferrándiz (2010).
} 
Aunque varios miembros del equipo y algunos de las personas que acudieron al acto llevaban camisetas o insignias con motivos republicanos, no hubo banderas ni cantos reivindicativos durante el acto ni durante el cortejo por las calles del pueblo camino del cementerio. Tampoco se celebró ceremonia religiosa durante el sepelio. Un aplauso siguió a la colocación de la lápida, que llevaba una nueva placa con los siete nombres y la inscripción: «Asesinados en Candeleda el 5 de octubre de 1936 por defender valores de justicia, libertad y democracia. Sus restos fueron recuperados en mayo de 2010 por la ARMH y enterrados en este lugar el 18 de marzo de 2011». Algunos de los familiares depositaron flores, encendieron velas y rezaron en voz baja. Otros permanecieron quietos. Reinaba un silencio cargado de emoción.

\section{Bucles necropolíticos: de la fosa común a la tumba a la fosa común}

Volvamos ahora a la casilla de salida. El 30 de julio se abrió la tumba y los restos, salvo los que presuntamente pertenecían a Virtudes de la Puente, fueron trasladaron cinco metros hacia el norte, a la "fosa común» municipal, situada cerca de la entrada del cementerio. Este traslado, realizado con la aprobación del alcalde de Poyales, provocó uno de los incidentes más graves desde que se iniciaron las exhumaciones en 2000, amplificada por el escándalo público y una cobertura mediática excepcional. Un factor fundamental que avivó la tensión fue que el alcalde del PP no había ponderado suficientemente cómo se interpretarían sus actos como responsable público en el contexto de las posiciones políticas adoptadas por su partido desde que comenzó el último ciclo de exhumaciones en el año 2000, consideradas vergonzosas y cómplices con el franquismo por las asociaciones memorialistas. El episodio ejemplifica, en primer lugar, la incomodidad con la que ciertas sensibilidades políticas en España están experimentando este proceso, ya sea explícita o implícitamente. En segundo lugar, muestra algunas de las fricciones que suelen producirse en las exhumaciones debido a discrepancias entre familiares (entre ellos y con políticos y asociaciones locales y nacionales); los desacuerdos entre las propias asociaciones; y la reconstrucción mediática de los hechos.

Dado que se había producido un ruido excesivo desde el desafortunado traslado de los cuerpos en el cementerio de Poyales, las versiones sobre lo sucedido diferían y prevalecía la desinformación, los insultos recíprocos y las medias 
verdades. Esperé a que la situación se calmara para volver a Poyales con el fin de hablar con Lázaro Martín. Él y su familia, afectados personalmente por el asunto del cementerio, no participaron en el enfrentamiento en el pueblo, no hicieron declaraciones a la prensa y desde entonces se mostraron esquivos con las asociaciones. "Fui yo quien decidió enterrar los siete cuerpos exhumados con las otras tres mujeres, y el alcalde estaba de acuerdo», señaló. Sin embargo, después de la inhumación, la nieta de Virtudes de la Puente se quejó a Lázaro y a los empleados del ayuntamiento porque consideraba que la sepultura era de su propiedad, pese a que el ayuntamiento se la había cedido temporalmente a ella y a los familiares de las otras dos mujeres. De hecho, en una circular del 22 de junio de 2011, el alcalde aseguraba que

al haberse mantenido una concesión graciable durante este tiempo por parte de los primeros beneficiarios [las tres mujeres de la exhumación de 2003], no se pueden presentar exigencias de ningún tipo por parte de éstos, ni siquiera que se trasladen los restos funerarios recientemente inhumados. Es más, este Ayuntamiento podría exigir que se trasladaran todos a la fosa común, que actualmente si existe, cosa que no va a suceder por respeto a los familiares (...) Por lo tanto, por parte de este Ayuntamiento se ha tomado la decisión de mantener todos los restos funerarios, tanto los originarios como los recientes (Entrevista del autor).

Sin embargo, después de algunas negociaciones en el pueblo, familiares y funcionarios acordaron informalmente el traslado de los siete cuerpos de la segunda exhumación a la fosa común junto a la entrada del cementerio, y la entrega a la familia de una de las mujeres de la primera exhumación, tal como se había solicitado. Pero una vez en el cementerio, algunas decisiones tomadas en el último momento provocaron una confusión considerable. Fue en ese momento cuando la inhumación y la reinhumación, hasta el momento circunscritas a las lógicas y significados locales, se conectaron con debates y controversias mucho más amplios sobre el destino de los restos exhumados en España en la actualidad. El abandono legal y en muchos casos político de los restos de republicanos exhumados desde 2000 impactó de lleno en esta historia local, sobredimensionándola. Los diez vecinos de Poyales recuperados quedaron en una situación vulnerable en el cementerio de su propio pueblo, muy distinta a la del resto de los vecinos enterrados allí. En su defensa del traslado, plasmada en una carta que firmó el 
10 de agosto de 2011 en la que califica las ejecuciones de la guerra, «de una y otra parte», como "horribles e injustos asesinatos» y pide disculpas por las consecuencias de la cadena de decisiones que generó tanta polémica, el alcalde aseguró que al abrir la sepultura inicial le sorprendió su mal estado, ya que estaba parcialmente inundada. Fue entonces cuando se decidió que todos los restos, salvo los que se atribuían a Virtudes (que fueron reinhumados ese mismo día junto con su hijo y su esposo), debían ser trasladados a la «fosa común» del cementerio, una ubicación más «distinguida» $\mathrm{y}$ "preferente» según el regidor.

Algunos miembros de la asociación local de la memoria histórica, que se encontraban en el lugar documentando el proceso de reubicación, acusaron rápidamente al alcalde de profanar la tumba y desmantelar una sepultura digna, revirtiéndola a una fosa común equivalente a la originaria. Posteriormente se convocó una manifestación de protesta contra el alcalde. En un comunicado, el Foro por la Memoria del Valle del Tiétar y La Vera, convocante de la concentración en Poyales, denunciaba la "profanación y destrucción de la tumba de diez víctimas de la guerra civil y el franquismo» en el cementerio. Calificaban este traslado como «un ultraje incalificable que merece ser llevado ante los tribunales penales». Y cerraban su declaración con las siguientes palabras, dirigidas a los diez fusilados: «no solo no os olvidamos. No consentimos, no aceptamos, no toleraremos que la impunidad se imponga ni que nadie no nada mancille vuestra truncada vida». Emilio Silva, por su parte, hizo un montaje de la tumba originaria antes y después de ser abierta, acompañado por el texto: "así quedó el nicho tras la actuación del alcalde de Poyales del Hoyo (PP), Antonio Cerro, que con todo su desprecio atentó contra los derechos humanos sin respetar principios básicos de la humanidad, el respeto que se merece todo ser humano, el cuidado de los seres queridos y el terrible sufrimiento que soportaron las familias de quienes fueron asesinados por la intolerancia».

Desde 2000 la partida de las exhumaciones se ha estado jugando simultáneamente en varios niveles, como muestra la forma en que una disputa local respecto a la ubicación de unos restos en un cementerio pasó al primer plano mediático, activando el sistema nervioso españo $l^{41}$. Lo que estaba en juego en el cementerio de Poyales no era solo una riña en un pequeño municipio, sino un debate fundamental, no resuelto y muy polémico de escala nacional: cómo gestionar las fosas comunes de la Guerra Civil y los restos de los civiles ejecutados, que se encuentran dispersos por todo el país.

41 Michael Taussig (1992). 
El 3 de diciembre de 2011, cuando el Tribunal Supremo estaba a punto de comenzar las audiencias públicas en el juicio de Garzón, me invitaron a una inusual reunión de estrategia conjunta entre la ARMH y el Foro celebrada en el sótano abarrotado de un bar de cañas y tapas del distrito de Hortaleza de Madrid, lugar de encuentro habitual de los activistas de la ARMH. Si bien la mayor parte del debate giró en torno a la adopción de tácticas comunes para responder al juicio de Garzón, el caso de Poyales se planteó al principio de la reunión, pues había enfrentado a las dos principales asociaciones y, en última instancia, había resultado doloroso y frustrante para todos. Uno de los participantes en la reunión, que había presenciado los incidentes en la plaza del pueblo, había presentado una denuncia por agresiones y pedía apoyo legal a ambas asociaciones. Algunos argumentaron que el caso era una flagrante violación de cualquier código ético mínimo y que, dada la reciente victoria electoral del PP, que había obtenido mayoría absoluta en el Parlamento, podría convertirse en un punto de inflexión en las políticas de la memoria de la Espańa contemporánea, echando a perder el trabajo de una década. Por ello, Poyales debía convertirse en un casus belli para el movimiento social de la memoria histórica. Durante la reunión se produjeron momentos de intenso debate. Finalmente, sin embargo, tanto el liderazgo de la ARMH como el del Foro aceptaron cierta responsabilidad en la mala gestión, acordaron entablar tenues acciones legales contra el alcalde y decidieron pasar página y mejorar los procedimientos para el futuro, especialmente la coordinación con las asociaciones y entre asociaciones y familiares y la consolidación legal de lugares de enterramiento en los cementerios para los exhumados. No obstante, después de una década de desacuerdos y enfrentamientos, la tregua fue precaria y solo duró unas semanas.

Los debates contemporáneos sobre la justicia transicional advierten de las dificultades que se presentan para lograr la rendición de cuentas, incluso aunque se hayan establecido "comisiones de la verdad» o aunque las leyes de "punto final» $\mathrm{y}$ "obediencia debida» hayan dan paso a los tribunales penales ${ }^{42}$. Hay autores que incluso cuestionan la lógica institucional, judicial y simbólica de tales mecanismos y la efectividad de «soluciones tecnocráticas y descontextualizadas» válidas para todos los $\operatorname{casos}^{43}$; también advierten de la posibilidad de que se produzcan «fricciones» y mayor sufrimiento con la aplicación de determinadas fórmulas de

42 Paloma Aguilar (2010).

43 Rosemary NagY (2008). 
reparación ${ }^{44}$, o subrayan la importancia de prestar más atención a micropolítica local de la reconciliación frente a los esquemas de reparación institucionales ${ }^{45}$.

$\mathrm{Al}$ analizar el proceso de las exhumaciones en España, el resultado de casi dos décadas de controversias sociales, políticas y judiciales es, en el nivel nacional, un sistema de subcontratación de la búsqueda de la verdad y la reparación en el que las instituciones del Estado, lejos de asumir la responsabilidad directa y de diseñar una arquitectura de verdad, justicia y reparación coherente, han optado por desempeñar un papel «facilitador», confiando la autogestión de las iniciativas de reparación en gran medida a las asociaciones y a la sociedad civil. En este modelo de reparación de abajo arriba, tareas cruciales tales como la localización de fosas, la investigación de archivos, la toma de testimonios, las exhumaciones, la atención psicológica, el trabajo de laboratorio, las identificaciones, los informes forenses y las reinhumaciones quedan en manos de asociaciones, familiares y equipos técnicos independientes, excepto en aquellas comunidades autónomas que han empezado a regular y protocolizar estas actividades.

Al mismo tiempo, tanto el sistema judicial como el Estado han contribuido a descarrilar los intentos de vincular las violaciones de los derechos humanos perpetradas contra la población civil durante la guerra y el franquismo con el derecho penal internacional. A pesar de la Ley de Memoria Histórica de 2007, los cuerpos de los ejecutados en las fosas comunes siguen encontrándose en un limbo judicial como delitos prescritos, y sus sentencias, en los casos en los que hubo juicios sumarios, siguen siendo firmes. La Ley de Amnistía de 1977 impide la investigación de responsabilidades penales. Hasta que el gobierno socialista hizo público oficialmente un protocolo nacional de exhumaciones, para el que hubo que esperar a octubre de 2011, España carecía de un protocolo unificado para la gestión, identificación o custodia de los cadáveres exhumados en muchas partes del país. Incidentes como los ocurridos en Candeleda y Poyales, aunque excepcionales en su grado de exposición pública, son indicativos de errores cruciales cometidos en la gestión contemporánea de un pasado traumático atribuible a la negligencia institucional y judicial y a las políticas de subcontratación de los derechos humanos. La precariedad en el traslado a los cementerios de los civiles republicanos ejecutados y abandonados en fosas comunes durante décadas también plantea dudas razonables sobre la capacidad a largo plazo de la prestigiosa

\footnotetext{
4 Alexander L. Hinton (2011).

45 Kimberly Theidon (2006); Kimberly Theidon (2012).
} 
transición espańola y su despliegue institucional en la mejora sostenida de la calidad democrática del país.

\section{Bibliografía}

Aguilar, Paloma (2000). Memory and Amnesia: The Role of the Spanish Civil War in the Transition to Democracy, Oxford: Berghahn Books.

Aguilar, Paloma (2010). "Transitional Justice in the Spanish, Argentinean and Chilean Cases», Workshop Report, Conference Building a Future on Peace and Justice, Nuremberg: Crisis Management Initiative.

Aguilar, Paloma y Payne, Leigh A. (2016). Revealing New Truths about Spain's Violent Past. Perpetrators' Confessions and Victim Exhumations, London: Palgrave Macmillan.

Álvaro Dueñas, Manuel (2006). Por ministerio de la ley y voluntad del Caudillo: la jurisdicción especial de responsabilidades politicas (1939-1945), Madrid: Centro de Estudios Políticos y Constitucionales.

BieHL, João (2001). «Vita: Life in a Zone of Social Abandonment», Social Text, 19:3 (2001), pp. 131-149.

Binford, Leigh (1996). The El Mozote Massacre: Anthropology and Human Rights, Tucson: The University of Arizona Press.

Bull, Ana Cento y Hansen, Hans Lauge (2016). «On Agonistic Memory», Memory Studies, 9 (4), pp. 390-404.

Casanova, Julián (1999). «Rebelión y revolución». En: Santos Juliá (eds.), Victimas de la Guerra Civil, Madrid: Temas de Hoy, pp. 57-177.

Casanova, Julián (2010). «The Faces of Terror: Violence During the Franco Dictatorship». En: Carlos Jérez-Farran y Samuel Amago (eds.): Unearthing Franco's Legacy: Mass Graves and the Recovery of Historical Memory in Spain, Notre Dame: University of Notre Dame Press, pp. 90-120.

Cowan, Jane K. (2006). "Culture and Rights after Culture and Rights», American Anthropologist, 108 (1), pp. 9-24.

Crossland, Zoe (2004). «Violent Spaces: Conflicts over the Reappearance of Argentina's Disappeared». En: John Schofield, William Gray y Collen M. Beck (eds.): Material Culture: The Archaeology of Twentieth Century Conflict, New York: Routledge, pp. 115-131. 
Crossland, Zoe (2011). "The Archaeology of Contemporary Conflict». En: Timothy Insoll (ed.): The Oxford Handbook of the Archaeology of Ritual and Religion, Oxford: Oxford University Press, pp. 285-306.

Edles, Laura D. (1998). Symbol and Ritual in the New Spain: The Transition to Democracy after Franco, Cambridge: Cambridge University Press.

Elkin, Michael (2006). «Opening Franco's graves: “The victims of Spain’s fascist past are beginning to tell their stories" ", Archaeology, 59 (5), pp. 38-43.

EtXeberria, Francisco (2004). «Panorama organizativo sobre Antropología y Patología Forense en España: Algunas propuestas para el estudio de fosas con restos humanos de la Guerra Civil española de 1936», en Emilio Silva, Asunción Esteban, Javier Castán y Salvador Pancho (eds.): La memoria de los olvidados, Valladolid: Ámbito, pp. 183-219. Versión online: http://www.sc.ehu.es/scrwwwsr/Medicina-Legal/_ private/AnPat.htm.

Fernández de Mata, Ignacio (2010). «The Rupture of the World and the Conflicts of Memory». En: Carlos Jérez-Farran y Samuel Amago (eds.): Unearthing Franco's Legacy: Mass Graves and the Recovery of Historical Memory in Spain, Notre Dame: University of Notre Dame Press, pp. 279-303.

Fernández de Mata, Ignacio (2016). Lloros vueltos puños. El conflicto de los «desaparecidos» y vencidos de la Guerra Civil española, Granada: Editorial Comares.

Ferrándiz, Francisco (2006). "The Return of Civil War Ghosts: The Ethnography of Exhumations in Contemporary Spain», Anthropology Today, 22 (3), pp.7-12.

FErrándiz, Francisco (2008). "Cries and Whispers: Exhuming and Narrating Defeat in Spain Today", Journal of Spanish Cultural Studies, 9 (2), pp.177-192.

Ferrándiz, Francisco (2009). "Fosas comunes, paisajes del terror», Revista de Dialectología y Tradiciones Populares, LXIV (1), pp. 61-94.

Ferrándiz, Francisco (2010a). "De las fosas comunes a los derechos humanos: El descubrimiento de las desapariciones forzadas en la España contemporánea", Revista de Antropología Social, 19, pp. 161-189.

FErrándiz, Francisco (2010b). "The Intimacy of Defeat». En: Carlos Jérez-Farran y Samuel Amago (eds.): Unearthing Franco's Legacy: Mass Graves and the Recovery of Historical Memory in Spain, Notre Dame: University of Notre Dame Press, pp. 304-325.

FERrándiz, Francisco (2011a). "Autopsia social de un subtierro", Isegoría, 45, pp. 524544.

FERrÁndiz, Francisco (2011b). "Guerras sin fin: guía para descifrar el Valle de los Caidos en la España Contemporánea». Política y Sociedad, 48 (3), pp. 481-500. 
Ferrándiz, Francisco (2013). «Exhuming the Defeated: Civil War mass graves in 21stcentury Spain», American Ethnologist, 40 (1), pp. 38-54.

FerRándiz, Francisco (2014). El pasado bajo tierra. Exhumaciones contemporáneas de la Guerra Civil, Barcelona: Grupo Editorial Siglo XXI/Anthropos.

González-Ruibal, Alfredo (2007). «Making Things Public: Archaeologies of the Spanish Civil War», Public Archaeology, 6 (4), pp. 203-226.

Hayner, Priscilla B. (2002). Unspeakable Truths: Facing the Challenge of Truth Commissions, New York: Routledge.

Hinton, Alexander L. (2011). «Introduction: Toward an Anthropology of Transitional Justice». En: Alexander L. Hinton (eds.), Transitional Justice: Global Mechanisms and Local Realities after Genocide and Mass Violence, New Jersey: Rutgers University Press, pp. 1-22.

Ignatieff, Michael (1998). The Warrior's Honor: Ethnic War and the Modern Conscience, Toronto: Penguin Books Canada.

Jérez-Farran Carlos y Amago, Samuel (eds.) (2010). Unearthing Franco’s Legacy: Mass Graves and the Recovery of Historical Memory in Spain, Notre Dame: University of Notre Dame Press.

Juliá, Santos (2003). «Echar al olvido: Memoria y amnistía en la transición», Claves de Razón Práctica, 129, pp. 14-24.

Juliá, Santos (coord.) (1999). Victimas de la Guerra Civil, Madrid: Temas de Hoy.

Keenan, Thomas y Weizman, Eyal (2012). Mengeles's Skull: The Advent of Forensic Aestehtics, Berlin: Stenberg Press.

Kuinenberg, E. (2001). «Bodies that Don't Matter: Death and Dereliction in Chicago». Body and Society, 7 (2-3), pp. 121-136.

Kwon, Heonik (2008). Ghosts of War in Vietnam, Cambridge: Cambridge University Press.

Labanyi, Jo (2008). Número especial sobre «The Politics of Memory in Contemporary Spain» del Journal of Spanish Cultural Studies.

Laqueur, Thomas (1989). «Bodies, Details, and the Humanitarian Narrative». En: Lynn Hunt (ed.): New Cultural History, Berkeley: University of California Press, pp. 176-204.

Laqueur, Thomas (2002). «The Dead Body and Human Rights». En: Sean T. Sweeney e Ian Hodder (eds.): The Body, Cambridge: Cambridge University Press, pp. 75-93.

Levy, Daniel y Sznaider, Natan (2002). "The Holocaust and the Formation of Cosmopolitan Memory», European Journal of Social Theory, 5 (1), pp. 87-106. 
López, Julián y Ferrándiz, Francisco (eds.) (2010). Fontanosas 1941-2006: Memoria de carne y hueso, Ciudad Real: Diputación de Ciudad Real.

Mвемвe, Achille (2003). «Necropolitics», Public Culture, 15:1, pp. 11-40.

Naciones Unidas (1991). Doc. E/ST/CSDHA/.12 Versión revisada en: http://www. ohchr.org/Documents/Issues/Executions/MinnesotaProtocolInvestigationPotentiallyUnlawfulDeath2016.pdf.

NAGY, Rosemary (2008). «Transitional Justice as Global Project: Critical Reflections», Third World Quarterly, 29 (2), pp. 275-289.

Preston, Paul (2011). El Holocausto español. Odio y exterminio en la Guerra Civil y después, Barcelona: Debate.

Renshaw, Layla (2011). Exhuming Loss: Memory, Materiality and the Mass Graves of the Spanish Civil War, Walnut Creek: Left Coast Press.

Ríos, Luis; Casado, José Ignacio y Puente, Jorge (2010). «Identification process in mass graves from the Spanish civil war», Forensic Science International, 199, e27-e33.

Robben, Antonius C.G.M. (2002). "State Terror in the Netherworld: Disappearance and Reburial in Argentina». En: Jeffrey A. Sluka (eds.): Death Squad: The Anthropology of State Terror, Philadelphia: University of Pennsylvania Press, pp. 91-113.

Robben, Antonius C.G.M. (2005). Political Violence and Trauma in Argentina, Philadelphia. University of Pennsylvania Press.

Rodrigo, Javier (2008). Hasta la raíz: Violencia durante la Guerra Civil y la dictadura franquista, Madrid: Alianza.

SAnford, Victoria (2003). Buried Secrets: Truth and Human Rights in Guatemala, New York: Palgrave MacMillan.

Sant Cassia, Paul (2005). Bodies of Evidence: Burial, Memory and the Recovery of Missing Persons in Cyprus, Oxford: Berghahn.

Silva, Emilio y Macías, Santiago (2003). Las fosas de Franco, Madrid: Temas de Hoy.

Taussig, Michael (1992). The Nervous System, New York: Routledge.

Theidon, Kimberly (2006). "Justice in Transition: The Micropolitics of Reconciliation in Postwar Peru», Journal of Conflict Resolution, 50 (3), pp. 433-457.

Theidon, Kimberly (2012). Intimate Enemies: Violence and Reconciliation in Peru, Philadelphia: University of Pennsylvania Press.

Tremlett, Giles (2006). Ghosts of Spain: Travels Through a Country's Hidden Past, London: Faber and Faber. 
Verdery, Katherine (1999). The Political Lives of Dead Bodies, New York: Columbia University Press.

VINYES, Ricard (2002). Irredentas. Las presas politicas y sus hijos en las cárceles franquistas, Madrid: Temas de Hoy.

WAgner, Sarah E. (2008). To Know Where he Lies: DNA Technology and the search for Srebrenica's Missing, Berkeley: University of California Press.

Wilson, Richard (2003). «Anthropological Studies of National Reconciliation Processes», Anthropological Theory, 3 (3), pp. 367-387.

Wilson, Richard (2006). «Afterword to 'Anthropology and Human Rights in a New Key: The Social Life of Human Right'», American Anthropologists, 108 (1), pp. 77-83.

Recibido: 25/07/2019

Aceptado: 22/10/2019

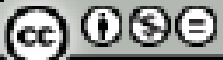

ENDOXA está bajo una licencia de Creative Commons Reconocimiento-NoComercial-SinObraDerivada 4.0 Internacional 